\title{
Methodical bases of forecasting volume of investments in innovative projects
}

\author{
Mezhov Stepan \\ Department of Finance and Credit \\ Altai State University \\ Barnaul, Russia
}

\author{
Shvakov Evgeny \\ Department of Finance and Credit \\ Altai State University \\ Barnaul, Russia
}

\begin{abstract}
Modern research, devoted to the transition of the Russian economy, to an innovative path of development, lacks the theoretical elaboration on the problems of formation of tools and mechanisms to improve management of modern innovationoriented corporations based on new methodologies and methods. The article offers a scientific and methodological approach to assessing the efficiency of innovative projects which develops and supplements the theoretical bases of innovative projects analysis through the accounting of recursive dependence of investments on such factors of innovative process as (1) the constructive complexity of the product, (2) the number of stages of the innovative process and (3) the innovative capacity of the enterprise. It is also proposed to introduce an adjustment factor (multiplier) to reflect the causal connection between the net present value of innovative projects and the abovementioned factors of innovative process and to improve the accuracy of calculation of cash flows under the project, linking the assessments with the certain stages of the project and the corporate capacity. This will reduce the overall integral risk of project implementation for potential investors.
\end{abstract}

Keywords-Innovations, modelling, strategy, multiplier, funding of innovative processes, net present value adjustment

\section{INTRODUCTION}

Global industrial development demonstrates the strengthening role of innovative production in mature economies. Innovations become the key factor of competitive capacity [4]. Taking into account the increasing backlog of Russian industry from many other countries, it needs intensive and scientifically grounded systemic modernization of the national economy. Opportunities for economic growth at the expense of oil and gas are exhausted, and the price of oil does not determine the dynamics of GDP growth.

The transition of Russian economy to the innovative path of development occurs under the lack of theoretical elaboration and the violation of principles of the systemic approach. In particular, the program documents do not provide a clear description of the mechanism and the concept of «material media» of innovative industrial transformations. They address side issues like intellectual property rights, venture funds, the support for young scientists and some others, which are important, but do not help solving the core problem of organization of mass knowledge-intensive production $[8,9]$.
One of the vital problems in managing a modern corporation is the construction of its economics in the line of innovative production. The science lacks the methodological substantiation of the concept of building the innovative economy. Therefore, there is a need of formation of theoretical and methodological foundations for the organization and management of modern innovation-oriented corporations in Russia.

Methodological aspects of this problem are reflected in the works on instrumental methods of research, i.e., on the assessment of innovative potential, the economic and mathematical modelling of innovation planning [2, 3, 5]. Still, there is no clear understanding that large industrial companies are the core of development strategies. Not enough attention is paid to the problem of innovation efficiency from the point of view of coordination of production and innovation processes at the industrial enterprise. Methods of corporate modelling require clarification and development to become the efficient planning tools.

\section{METHODOLOGY}

A production program is the most important element of corporate planning. At that, this task allows rather clear formalization and application of programming tools of decision-making. A production program stipulates optimum availability of resources and calculates all the technical, economic, and financial indicators and parameters. However, production planning is much more complicated for an enterprise which competitive capacity is based on innovations and constant launch of new products. The authors take as a premise that (1) production plans should include the planning of innovations and investments in innovations; (2) assessment of investment efficiency requires a simultaneous and coordinated forecast of cash flows from all activities; and (3) the production planning shall be a long-term prospective forecast.

The research of production structures with innovative potential that allows covering all the stages of innovation process on the basis of constant renewal of products and receiving the rent during a long period of time methodologically relies on the introduced notion of an innovation-oriented corporation. This notion summarizes and systemizes those variants of defining the enterprises oriented to innovations which are most popular in scientific literature. 


\section{THE ECONOMIC MECHANISM OF CORPORATION SUSTAINABLE} DEVELOPMENT

At the end of the XX - beginning of the XXI century, the leading industrial corporations underwent a large-scale reconstruction following the new paradigm of organization of business and competition: a modern enterprise is a multilayer structure that integrates in time and space the flows of resources, which evolve at a different speed $[1,6,9,12,14$, 16]. At that, the category of «resource» is significantly expanding and is supplemented with the notions of «key competences», «dynamic abilities», and «routines».

Such corporations successfully combine the tactical and strategical aspects of their activity. What is the foundation for the economics of a leading western or Japanese company? It definitely possesses enough assets, the technology relevant to the industry development level, the $R \& D$ facilities, the market share and cost structure that ensure balanced production of goods and innovations with a pre-set standard return on assets.

The hypothesis is that such innovation-oriented corporation shall follow certain functional relations between key parameters such as equity, output and sales, production and innovation costs, return on investment (ROI), and etc. Speaking about innovations, one has to understand how they are financed, how the strategic stability is ensured, and how the balance between the initial costs and return is reached.

The study and research are focused on the following concept: speaking about innovations, one has to see the main outcome in the form of cash income $[10,11]$. ROI is a return on capital: intellectual, technical, and managerial. How will this capital work in a Corporation?

A competitive production of a modern corporation consists of the processes of production (operations) and innovations. An operational process means solving current tasks of production and sales of products. It is the source of financial resources for all forms of investments including innovations. The process of innovations solves the prospective tasks for future production (transfer of competition from the sphere of production to the sphere of innovations). The processes of operations and innovations have a sequential and parallel logic of interaction and can be formally presented as a set of life cycles. Consequently, a modern corporation has certain proportions between the processes of operations and innovations which shall be reflected in the production plan.

\section{A. Model of planning new products in conditions of constant investment in innovations}

It offers a concept of the Operations and Innovations Programme $(O I P)$ as a unified and balanced in the selected time interval plan of production and sales of products and innovative works on the preparation of production of promising products substituting phase out products [10]. The main task of such program is to synthesise models of innovative and production processes in a way ensuring a rational combination of limited resources for production of goods and innovations with an increase or, at least, the maintenance of competitive capacity in the strategic perspective. tasks:

For this purpose, such planning shall resolve the following

- Preparation of an optimum production plan, taking into account the demand, the available resources, and the development strategies.

- Definition of suitable investment funding strategies and the assessment of return in the form of rent and profit.

- Definition of time of the launch of new products and the withdrawal from production of the old ones.

- Balancing the operations and innovations in the program through the calculation of financial indicators, forecasting the balance and preparation of data for the start of the next iteration in the planning interval.

This model includes forecasting blocks of the operational plan, the choice of an implementation strategy of the innovation process and the assessment of investment efficiency. The purpose of the model: to determine the optimum structure of production oriented to market demand, the assessment of investment funding strategies including the assessment of the innovative potential and the stage of $R T D$ funding. It is also used to forecast the payback of a new product, to calculate the income and rent using such data as forecasted live cycles of each product, the financial and economic characteristics of the enterprise and some others. The balance of model calculations between the operational and innovational parts of the OIP is ensured by the Higgins model [7] which shows how the assets and a number of other financial indicators shall change under changing sales and costs.

The demand for products is forecasted by $N$ application of Monte-Carlo method to the life cycle interval, with the subsequent averaging. At that, marketing department shall define the forecasted demand for a new product within the developed market development strategy. This demand will represent exogenous parameters of the simulation.

The "Functions Costs-Sales" block sets the sales (based of forecasted demand), costs and profit functional parameters for each product while the integral characteristics may be obtained from corporate reports. These functions are the basis for criteria, constraints on costs, output, and capacity of the optimization model.

The optimization model is formed automatically. The results are first processed by the "Calculation of financial indicator" block, then - by the "Calculation of innovation and investment indicators" block to obtain $N P V$, the payback period, $N P V$ adjustment, and rent assessment, define the final parameters, and deliver the variants of $O I P$.

The general algorithm for the modeling of operational and innovation program is as follows:

1. On the basis of retrospective and analytical data of the enterprise, you can form a file of life cycles of production of main products; if necessary, the procedure for the aggregation of similar nomenclature items can be carried out. 
2. Dependencies on the planning time of sales (demand) for each product, based on marketing data, can be combined in the tabular form, additionally including the standard deviation for each product in it. Obviously, the forecasting of the random variable of "demand", based on the life cycle curve, is due to the presence of this value in the interval, for example, according to equation (2): the life cycle of the $j$ product is denoted as $G_{j}, j=1,2 \ldots J$, then $J$ products can have various product life cycles as a continuous time function:

$$
G_{j}=G_{j}(t) \text {, }
$$

or as a discrete, tabular form of a task, in the form of compliance:

$$
\begin{gathered}
G_{j}^{i}-t_{j}^{i} ; j=1,2 \ldots J ; i=1,2 \ldots \pi, i-\text { numbers of time } \\
\text { periods, }
\end{gathered}
$$

$\pi-$ a number of discrete partitions of the table (a number of years).

In fact it is possible to have both the analytical dependence, for instance, sales volume depends on the time, and a tabular dependence with the corresponding derived indicators, such as income, expenses, etc. All these indicators can be represented both in value and natural forms.

to build the analytical dependences used regression analysis, then the curve $M\left(G_{j}(t)\right)$ represents an average value of the fluctuations in sales over time. In a regression analysis determined the standard deviation of sales $-\sigma_{j}\left(t_{k}\right)$ using Monte Carlo modeling method, where $t_{k}$ means the time of forecasting the volume of demand. Thus, $\sigma_{j}\left(t_{k}\right)$ shall be different for different time intervals, which is natural, since this standard deviation reflects the average spread of demand in different time intervals of forecasting. Obviously, the acceptable value of sales in the planning, according to the law of three sigma, may lie with high probability in the following interval:

$$
M\left(G_{j}(t)\right)-2 \sigma_{j}\left(t_{k}\right) \leq G_{j}(t) \leq M\left(G_{j}(t)\right)+2 \sigma_{j}\left(t_{k}\right)
$$

In the presence of available life cycles of all products: $G_{j}=$ $G_{j}(t), j=1,2, \ldots, J$; planning time, or at discrete consideration, specifying the demand forecast (2), it is necessary to find an optimal production schedule in physical indicators at time $t$ :

$$
x_{j}^{t} \leq G_{j}^{*}(t) ; x_{j}^{t} \in X_{t} ; t=1,2, \ldots, T ; j=1,2, \ldots, J,
$$$$
x_{j *}^{t}=(1-\alpha) x_{j *}^{t 1} ; x_{n j *}^{t}=\alpha x_{n j *}^{t 1} \text {. }
$$

where $X_{t}$ means an optimal plan, $x_{j}^{t}$ means nomenclature plan components, $\alpha$ - a control parameter, the share of new products to replace the old ones.

With $\alpha=0$, a new product is not included in the program; when $\alpha=1$, an old product is completely excluded from the program; with $0<\alpha<1$ both products in the proportions shown in the equation (4) are included in the program.

$x_{j *}^{t 1} \quad$ means a product being excluded from the program; $x_{n j *}^{t 1}$ means a new product launched into production; $t_{1}$ means the time of the product replacement.

3 . For each product $j$, let us form the functions of costs and sales, using the second order polynomials by the regression analysis. If there are the functions of costs and sales by linear functions, then for sales volume it is necessary to know the price of each product, variable costs and fixed costs: in total for the program and for each product separately.

4. Demand forecast $G_{j}^{w}$ for products $j$ based on product life cycles shall be carried out on the basis of the Monte Carlo algorithm, allowing for each product to form restrictions of the following type for the optimization model of the production program:

$$
X_{j} \leq G_{j}^{w} \leq X_{j}^{m}
$$

Production capacity determines the limiting boundaries of the output: if the demand forecast for a product is less than the output capacity of the same product, i.e. $G_{j}(t)<X_{j}^{m}$, then $\mathrm{x}_{j}^{t} \leq G j,(t)$; and if $G j,(t)>X_{j}^{m}$, then $\mathrm{x}_{j}^{t} \leq X_{j}^{m}$. It means that when demand exceeds the capacity, the value of an expected volume does not exceed the capacity if it does not provide an additional product launch.

This intermediate restriction is necessary to consider the production capacity for each product: it suggests that upper random forecasting limit $G_{j}^{w}$ should not exceed the production capacity for this product.

5. Let us form the optimization model and calculate the optimal program.

6. Let us form options investment strategies for the product being replaced by $j^{*}$. The options strategies are conditioned by the investment volume and rate, the nature of the investment at stages of the innovation process, the rate of production growth up to the project level and the payback period. Examples of strategies include such options as the uniform investment at all stages of the innovation process in large volumes in the early stages; investments in new technologies and organization of production,increase of innovative potential, etc. The replacement strategy consists of two vectors. The elements of the first vector show the volume of investments for each year. The second vector shows a mechanism for replacement of an "old" product on a "new" one.

7. For each variant of product replacement with a new one (the analog of the investment project), the NPV is calculated. Let us forecast the NPV equal to zero and define the term expected payback of the project when launching a new product, which is included in this version of the strategy evaluation of the initial investment $I_{n}$.

8. The source of financing (covering) $I_{n}$ is a part of fixed costs of the enterprise. The total amount of investment in innovation is distributed for the project period in accordance with an option of the replacement strategy of this algorithm, so that:

$$
I_{n}=\sum_{t=1}^{T}\left(1-\lambda_{t}\right) I
$$

$\lambda$ indicates the share of investments in production, while (1$\lambda$ ) indicates the share of investment in innovation, at the same time $I$ - is the amount of investment in OIP, in the optimization model it serves as the right part of restrictions on the volume of investment in the entire program of current production and innovations. The mechanism of the ratio is as 
follows: the volume of innovation investment for the following year $I_{n t+1}$ is formed due to the undistributed profit for preceding year $t$ and general fixed costs.

9. Then let us turn to the calculation of the financial parameters and indicators, as well as the parameters of sustainable growth.

10. Paragraphs 6 and 8 shall be repeated for all options of replacement strategies.

11. Le tus select the version of the decision that is the most satisfactory in cost and time criteria.

When modelling the OIP (Fig. 1), each planning stage shall deliver a separate optimization model with its own on investments, the calculation of rent from production and sales of a new product.

Innovative potential assessed through processing the results of questioning the experts is not a constant value. This potential is a dynamic parameter which varies depending on the volume and intensity of investments in innovations. According to methodology, the increase in innovative potential reduces the adjustment factor and the payback period of an innovative project for launching a new product.

The development and future production of a new product suggest the receipt of Schumpeterian (business) rents what should be taken into account in the simulation by changing the price of the new product. Price of a new product depends on

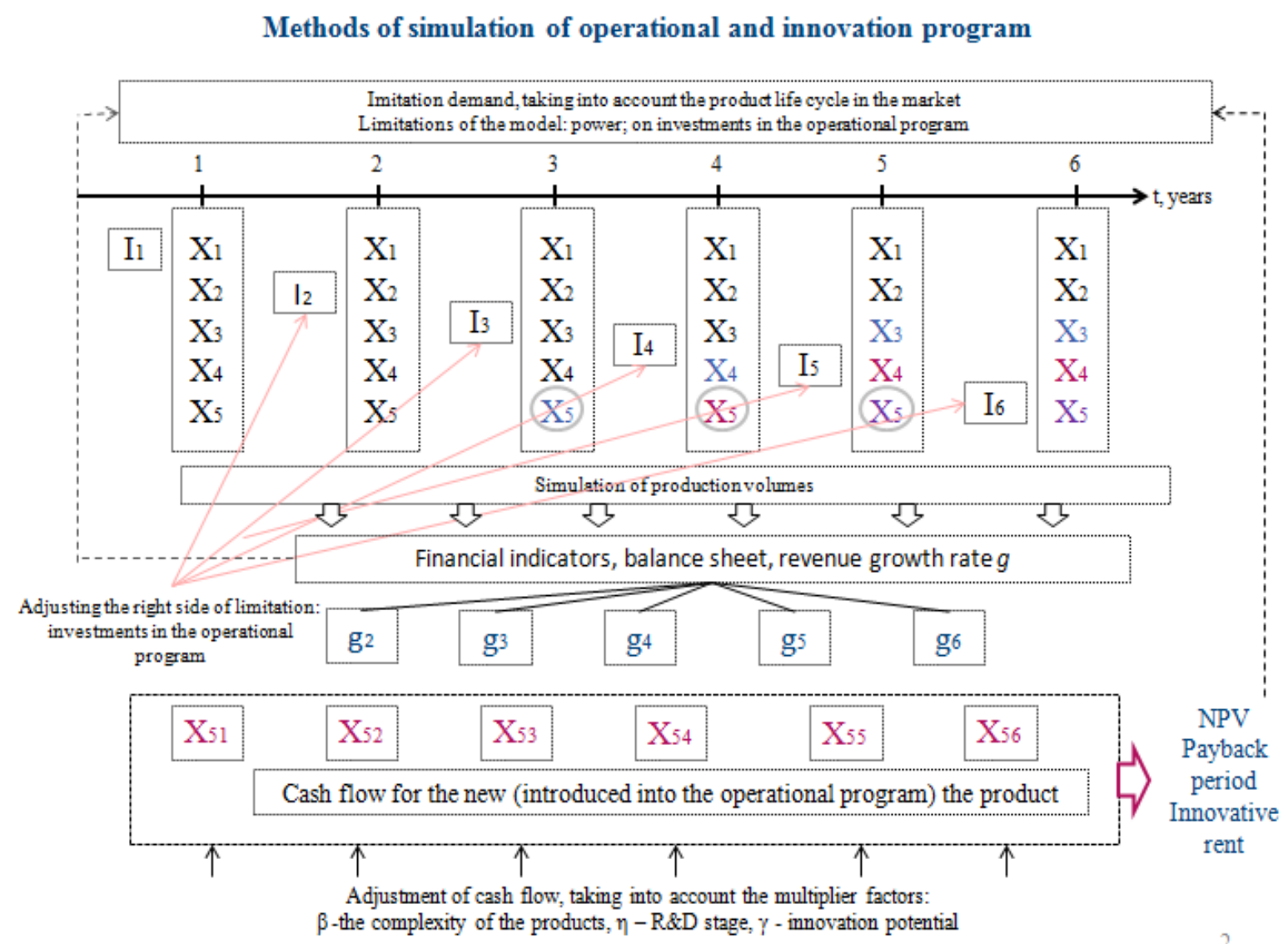

Fig. 1. OIP modelling approach

parameters and constraints defined by the current state of corporate resources at the moment $t$.

Balance sheet indicators are simulated using the optimization model [9]. Financial indicators are calculated using balance sheet calculations for each forecasting year.

The block of calculation of investment characteristics solves the following tasks: the assessment of $R \& D$ investment efficiency, the calculation of NPV, the adjustment of NPV taking into account the current innovative potential, the consideration of changes in the innovative potential depending the competitive influence on the market. The rent to be received from production and sales of the new product is calculated for the strategies defined by the marketing department.

The methodological statements allow adjusting the volume of investments in innovations taking into account the payback periods and the balanced growth rates. 
B. Assessment of the volume of investments in OIP innovative project

The prepared OIP model addresses rather important theoretical and practical issues related to the dependence of the volume of investments on the characteristics of the innovation process and the level of corporate innovative potential. Technological parameters and the innovative potential in general have a definite but not a direct influence on the efficiency of innovative projects. An accurate assessment of investments, efficiency and payback period of innovative project based on $N P V$ requires a methodical approach to the investment analysis of innovative projects which would take into account the technological and organizational characteristics of the corporation.

More accurate definition of investments in innovations and the assessment of $R O I$ require clarifying the basic $N P V$ concept from the point of dependence of the result from the complexity of the product, the depth of the innovative process and the innovative potential of the enterprise by including these characteristics in the $N P V$ calculation formula.

The analysis of scientific literature on the issue and assessment of efficiency of innovative projects shows that the existing methods do not take into account a number of essential factors that will be mentioned below.

Total expenses on innovations in an industrial corporation include expenses on purchasing the scientific equipment, apparatus, software, wages of scientists and engineers, patent and informational support, outsourcing of works and financing of certain projects. Expected income of a classical investment project mainly depends on the amount of investments, rate of return $(R O R)$ and risk, while an innovative project has a complex systemic dependence mainly from technical and economic, or technological factors.

Formally, the forecasted investments in an innovative project $I_{n}$ depend on a certain set of parameters and factors:

$$
I_{n} \leq \Psi\left(c_{n j *}, x_{n j *}, \delta, \beta, \eta, \gamma, T_{n}\right)
$$

where $c_{n j *}$ is the expected price of a developed innovation product $j *$ substituting the "old" product $\mathrm{j} ; x_{n j *}$ is the expected total output of the new products; $\delta$ is the planned ROR including the risks and the required ROR defined by the corporate management; $\Psi$ is the type of function; $\beta$ is the structural complexity of the product which may be assessed by an expert or analytically in comparison to an analogue; $\eta$ is the depth of scientific study (the development of theory, survey, technology) which reflects the level of spending on $R \& D$ stages; $\gamma$ is the integral criterion of scientific and production potential which reflects the availability of key competences, routines, the level of equipment of laboratories, and the similar depth of penetration of the industry. I.e., the corporation as an average representative of the industry has its history, a stable market share, the innovations, and etc.; $T_{n}$ is the payback period defined for a fixed level of investment.

According to the procedures for assessing the technological parameters and innovative potential offered by [10], the structural complexity of the product, the depth of innovative process, the innovative potential of an enterprise can be assessed through questioning the qualified experts in the fields of science and production.

The substantiation of the concept will be based on the following:

A corporation with a high innovative potential, competences and abilities will require less investment in $R \& D$ to create the same product than a corporation with a smaller potential. In the current term, it will spend less on preproduction and research equipment and training as it has more qualified staff, a developed scientific and production base, an information base and essential reserves in many directions of development. The corporate experience also has a great meaning.

In the absence of potential $(\gamma \rightarrow 0)$, the costs of innovations are very large; and vice versa, the higher is the potential, the lower is the cost of innovations.

A corporation can become innovative at any stage: the basic research, the applied research, or can get a patent and start developing a concept product and the design. From the strategic point of view, its decision-makers have to decide on their intentions: do they want to start the research at an early stage with higher In, to create key competences and routines for this area and to gain additional income (rent), or they want to save In but to lose the rent as the competitors will also be able to deliver this product.

Some properties of exponential function allow building models of accounting and analysis of investments in innovations, especially, through defining the $\alpha$ argument by regression analysis on the basis of the available dynamic ranks.

Let's see how the parameters of innovative potential affect the $N P V$. It defined that the higher is the potential $\gamma$, the less initial capital is required, and vice versa. Also, the deeper is the innovative process $\eta$, the more funds are required for its implementation. The same refers to the product complexity: the more complex is the product (the greater the value of the coefficient $\beta$ ), the more investments are needed.

Complex influence of these characterizing factors of an innovative project and the enterprise itself can be taken into account by introducing a special multiplier (adjustment factor), for example, by using an exponential function,

$$
\sigma=e^{\frac{b \beta \eta}{\gamma}}
$$

where $b$ is the coefficient taking into account the cost forecasting accuracy in development of complex products.

The parameter $b$ can reflect the degree of inaccuracy of the planned investment decisions and can be defined by an expert. I.e., if 6 out of 10 planned investment decisions with the preset parameters in average have significant deviations of actual parameters from the planned ones, then this parameter is equal to 0.4 . The coefficient $b$ shall be defined by the experts from the corporate planning services, and this parameter is adjustable.

Then let us define properties of expression (7) taking into account that function indicator $\sigma$ has the following restrictions: 
$0 \leq \beta \leq 1 ; 0 \leq \eta \leq 1 ; \gamma \mathrm{d} \leq \gamma \leq 1$

$\sigma=1$, if $\beta=0 \vee \eta=0 ; \sigma>1 ; 1$ if $\beta \neq 0 \vee \eta \neq 0$. Here, "v" means logical operator "or". But b can be equal to 0 , so the planned system absolutely precisely defines the efficiency of investments as $\sigma=e^{0}=1$. Therefore, the correcting coefficient simply does not influence the investment project efficiency level.

$\sigma \rightarrow \infty$, at $\gamma \rightarrow 0$. That means $\sigma$ is significantly growing with a decrease of innovative potential $\gamma$.

As the coefficients of complexity and depth are in the range of $0 \leq \beta \eta \leq 1$, then the variable $\frac{b \beta \eta}{\gamma}$ has the maximum value when $\gamma=\gamma d, \beta \eta=1$, that means, when the product has the highest complexity and the lowest level of preparedness, and the potential $\gamma$ is at extremely low level. Considering that the minimum value of $\sigma=1$ with the set restrictions on dimension parameters, it means that the values of $\beta$ and $\eta$ (characteristics of a certain innovative project) for various values of $\gamma$ with the adjustment factor $b$ are required to calculate the usual NPV (without adjustment).

The parameter $b$ is used to "set" the multiplier $\sigma$ for a certain enterprise taking into account its technical and organizational characteristics and the statistics of investments in different projects.

The innovative project investment strategies will be integrally assessed using the adjusted $N P V$ calculation procedure. The concept has used the innovative potential of the enterprise, the product complexity, the depth of $R \& D$ and the multiplier to obtain an equation for assessing the amount of initial investments in an innovative project depending on the characteristics of the innovative process:

1. $\rho_{n j *}$ is the return on current costs on production $x_{n j *}$, and is the sum of the return on costs $R c_{n j *}$ and the additional yield from the Schumpeterian rent $\operatorname{Ren}_{j *}$ :

$$
\rho_{n j *}=R c_{n j *}+R e n_{n j *}
$$

2. The product price is the production of yield and costs $S_{n t}$ in period $t$ :

$$
c_{n j *}=S_{n t}+\rho_{n j *} S_{n t}=\left(1+\rho_{n j *}\right) S_{n t}
$$

With the adjustment, the NPV calculation formula will look as follows:

$N P V=-I_{n}^{\Pi}+\sum_{t=1}^{T} \frac{(1-\tau)\left(R c_{n j *} S_{n j *} x_{n j t *}+R e n_{n j *} S_{n j *} x_{n j t *}-S_{c n s j *}\right)}{(1+\delta)^{t}}$

Let us transform the formula (5) into the equation for the case when NPV $=0$ to receive the equation for assessing the amount of initial investments in an innovative project depending on the characteristics of the innovative process:

NPV $=$
$-I_{n}^{\Pi} e^{\frac{\mathrm{b} \beta \eta}{\gamma}}+\sum_{t=T 1+1}^{T} \frac{(1-\tau)\left(R c_{n j *} S_{n j *} x_{n j t *}+R e n_{n j *} S_{n j *} x_{n j t *}-S_{c n s j *}\right)}{(1+\delta)^{t}}$ where $T 1$ is the time spent on $R \& D, \tau$ is the income tax rate.

Here, the production $R \mathrm{c}_{n j *} S_{n j *} x_{n j t *}$ represents the operating income, and $\operatorname{Ren}_{n j *} S_{n j *} x_{n j t *}$ is the rental income from the competitive advantage of the corporation. In competitive environment, the corporations follow up with promising products and the yield gradually decreases to reach the industry average.

So the amount of investments in complete development of an innovative product including the launch of its production is within the interval bounded from below by the planned output, and from the top - by the adjusted amount of investments taking into account the structural complexity of the product, the number of stages of scientific development, and the scientific and production potential of the enterprise. The top bound of the interval mostly depends on the innovative potential which structure depends on the technological level, the human capital, the $R \& D$, and etc. The higher is the innovative potential, the shorter is the interval; than the forecast of the actual investments in innovations is more accurate.

Preparation of raw data, calculation of such parameters as the innovative potential, the depth of the innovative process, the forecasted values of demand, prices and costs of the products, and formation of strategies of launching the new product are followed by the assessment of strategies of the OIP models and the selection of optimum variant by certain criteria.

\section{CONCLUSION}

The offered theoretical and methodological provisions and recommendations were tested using model calculations based on real data and have proven their consistency and suitability for innovation planning. These recommendations can be introduced in the management practice of Russian corporations.

The developed original OIP model combines the formal description of operational and innovation processes of an enterprise for the needs of production planning, forecasting the demand based on live cycles, planning the launch of new products and removal of the old ones, assessing different strategies of investment in $R \& D$, its launch and sales.

It also allows assessing the efficiency of an innovative project taking into account the innovative potential, the depth of innovative process and the complexity of the product by including in the calculation of cash flows the forecasted values of the OIP operational component.

\section{References}

[1] M. A. Al-Fawzan, \& A. Al-Hargan, "Promoting techno-entrepreneurship through incubation: An overview at BADIR program for technology incubators", Innovation: Management, Policy and Practice, 16(2), pp. 238-249, 2014.

[2] A. Baniak, I. Dubina, "Innovation Analysis and Game Theory: A Review", Innovation: Management, Policy and Practice, 14(2), pp. 178191, 2012. 
[3] E. Carayannis, Y. Goletsis, E. Grigoroudis, "Multi-level multi-stage efficiency measurement: the case of innovation systems", Operational Research: An International Journal, 15(2), pp. 253-274, 2015.

[4] H. Chesbrough, J. West, W. Vanhaverbeke, Open Innovation: Researching a New Paradigm, Oxford University Press, Oxford, 2006.

[5] V. Danilin, Operational and financial planning in the corporation (methods and models), Publishing House "Science", Moscow, 2006.

[6] I. Gurkov, Why Some Russian Industrial Companies Innovate Regularly: Determinants of Firms' Decisions to Innovate and Associated Routines, Journal for East European Management Studies, Vol. 18. Is. 1, 2013.

[7] R. Higgins, Analysis for Financial Management, 10th edn, the McGrawHill/Irwin series in finance, insurance and real estate), New York, NY 10020, 2012.

[8] G. Kleyner, Strategy of the company, Publishing House "Delo", Moscow, 2012.

[9] V. Kondratyev, "Corporate sector and the state in the strategy of global competitive capacity", World Economy and International Relations 3, pp. 24-31, 2009.
[10] I. Mezhov, S. Mezhov, "Formation of the model of effective investment of industrial innovations", Management in Russia and abroad, vol. 4, pp. 39-47, 2011.

[11] S. Mezhov, "The concept of corporate Operations and Innovations Programme", Problems of theory and practice of management, vol. 2, pp. 85-94, 2010.

[12] A. Rosiello, M. Mastroeni, M. Teubal, G. Avnimelech, "Evolutionary Policy Targeting: Towards a Conceptual Framework for Effective Policy Intervention", Technology Analysis \& Strategic Management, vol. 25(7), pp. 753-772, 2013.

[13] A.N. Shichkov, The Theory and Practice of Engineering Business and Management in a Municipality, Vologda: VSU, 119 p., 2016.

[14] Science \& innovation investment framework 2004 - 2014, BBC News, URL:http://news.bbc.co.uk/nol/shared/bsp/hi/pdfs/science_innovation_1 20704.pdf.

[15] J. Schumpeter, Capitalism, Socialism, and Democracy, Taylor\&Francis e-lib-rary publishing, First published in the UK in 1943, 2003.

[16] G. Untura, "Strategic support of the Russian regions: Problems of the assessment of the status of innovative territories", Regional Research of Russia, vol. 3, Iss. 2, pp. 153-161, 2013. 